\title{
3D-CFD Study of Oblique Streamlining Membranes on the Roof-Top of a Low-Rise Building, Targeting Pedestrian Comfort - A Case Study
}

\author{
Alireza Mani ${ }^{1}$, Kasra Amini ${ }^{2,3 *}$ (1) \\ ${ }^{1}$ Department of Mechanical Engineering, Sharif University of Technology, Tehran, Iran \\ ${ }^{2}$ Faculty of Mechanical Engineering, RWTH Aachen University, Aachen, Germany \\ ${ }^{3}$ Institute of Aircraft Propulsion Systems (ILA), University of Stuttgart, Stuttgart, Germany \\ E-mail: kasra.amini@rwth-aachen.de
}

Received: 1 June 2020; Revised: 12 September 2020; Accepted: 28 October 2020

\begin{abstract}
Considering the cubic nature of the most frequent geometries among the urban elements and their configurations, the manipulation of the free stream wind flow around the enormous objects, as well as within relatively narrow corridors, such as street canyons is significant in many regards. One of its instances could be mentioned as pedestrian comfort. In this case study, the implementation of an Oblique Streamlining Membrane (OSM) has been studied on a sub-branch of a low rise, but bulky, building, over which a roof-top outdoor food court area has been primarily designed. The OSM serves as the streamlining mechanism, preventing the roof-top area from the intense fluctuations of the wind flow after the flow is separated from the inlet corner side of the building in question. The optimization of sub-geometries and the proof of the concept for the OSM flow controlling mechanism were the subject of the current manuscript, for which a 3D numerical Reynolds Average Navier-Stokes (RANS) scheme has been used. An unstructured computational grid has been applied around the 3D geometry of the entire building and its subbranching details, which is in contrast with most studies on full-scale geometries, tending to have simplifications on the body to reach a more generalized set of results. All cases have been numerically tested with and without the presence of the OSM. This comparison has been the grounds for proving the effectivity of the said flow controlling mechanism to eliminate high gradient fluctuations of the separated flow off the roof corners. This has led to pedestrian/resident comfort on the roof-top food court area located on top of the building.
\end{abstract}

Keywords: building aerodynamics, flow control, Computational Fluid Dynamics (CFD), pedestrian comfort, Oblique Streamlining Membrane (OSM)

\section{Nomenclature}

$\begin{array}{ll}\text { Latin Letters } \\ \mathrm{U} & \text { Inlet wind velocity } \\ \mathrm{D} & \text { Cross-diffusion term } \\ \vec{F} & \text { External body force } \\ \bar{G} & \text { Generation } \\ \mathrm{H} & \text { Energy }\end{array}$

Copyright (C2020 Kasra Amini, et al.

DOI: https://doi.org/10.37256/gbce.112020448

This is an open-access article distributed under a CC BY license

(Creative Commons Attribution 4.0 International License)

https://creativecommons.org/licenses/by/4.0/ 


$\begin{array}{ll}\mathrm{I} & \text { Unit tensor } \\ \mathrm{J} & \text { Mass flux } \\ \mathrm{k} & \text { Thermal conductivity } \\ \mathrm{p} & \text { Static pressure } \\ \mathrm{S} & \text { Source term } \\ v & \text { Velocity component } \\ \mathrm{T} & \text { Temperature } \\ \mathrm{Y} & \text { Dissipation due to turbulence } \\ \text { Greek Letters } \\ \mu & \text { Dynamic viscosity } \\ \rho & \text { Density } \\ \tau & \text { Shear stress } \\ \Gamma & \text { Effective diffusivity } \\ \text { Abbreviations } \\ \text { CFD } & \text { Computational Fluid Dynamics } \\ \text { OSM } & \text { Oblique Streamlining Membrane } \\ \text { RANS } & \text { Reynolds Average Navier-Stokes } \\ \text { ABL } & \text { Atmospheric Boundary Layer } \\ \text { Subscripts } & \\ \mathrm{m} & \text { Mass } \\ \omega & \text { Specific dissipation rate } \\ \text { Eff } & \text { Effective } \\ & \end{array}$

\section{Introduction}

The industrial urge of placing an ever-increasing magnitude of urban elements in the developed modern world is faced with numerous challenges in terms of traffic control, energy supplement, and so forth. The balance between the two ends of this compensation is constantly under threat through industrial demands, and the technological advancements in response to them to meet the criteria for a compensation once more.

One area of such interaction could be found due to the matter caused by enormous urban elements in regard to their surrounding flow fields. The significant blockage of the wind flow in comparison to the small semi-venturi type openings between the buildings leads to the induction of relatively high gradients in the velocity profile. The unsteady nature of such a velocity profile as well as the absolute magnitude of the local velocity vectors at some points of the domain leads to a condition known in the field as 'pedestrian discomfort'. Overcoming the problems raised by the abovementioned conditions has been the essence for the emergence of the field of urban aerodynamics as a part of the overall subject matter of building physics.

Castro and Robins [1] investigated the theoretical background for the turbulence flows around a surface mounted cubic objects. The results are transferable to building aerodynamics as the geometry in question resembles the most commonly used form in the modern urban architecture. Cemak [2] covered a variety of fluid mechanics applications in the field of wind engineering and industrial aerodynamics. Irwin [3] addressed the more specific applied study of the bluff body aerodynamics in the mentioned field.

Richards and Hoxey [4, 5], investigated the pressure field applied by the atmospheric wind flow profile on a cubic body of $6 \mathrm{~m}$ in magnitude. And then directly report the results on the loadings exerted on the geometry by the flow field.

On the specific case of convective heat transfer coefficient within the applications of the building aerodynamics and urban physics, Mirsadeghi et al. [6] served as a literature review. Whereas Defraeye et al. [7] presented a study on the existing correlations and models in CFD.

While the studies on a varied range of fluid flow aspects in the field of building aerodynamics are numerous, the more direct correlation between the phenomena of pedestrian comfort is to be looked for in the external flow field studies. Van Hooff and Blocken [8], however, combined the interior and exterior flow fields in regard to the indoor 
natural ventilation modelling and the overall exterior flow field on a high-resolution numerical grid, for the specific case of the Amsterdam Arena stadium. Shi et al. [9] Provided insight on the requirements and assessment of pedestrian wind comfort, while Aregger and Glaus [10] studied the issue for the case of high-rise buildings.

In a comprehensive work, Blocken [11] presented information on distinct aspects of the numerical analysis in urban physics. Amini et al. [12] investigated the external flow field of a smart house prototype by implementing a flow control mechanism all around the periphery of the building. The mechanism is put in place to minimize the convective heat transfer capacity of the external flow as well as reducing the drag force exerted on the structure by the wind. In previous study shown by Amini and Mani [13], a bigger in size but less complicated in design type of flow control mechanism has been tested numerically and proven to moderate the flow separation off the lee side of a gable roof geometry.

Tominaga et al. [14] provided a guideline for CFD analyses focusing on the pedestrian wind environment conditions around buildings. Blocken et al. [15] addressed the flow in a street canyon of parallel buildings from a CFD evaluation perspective. The case for the building interference effects on pedestrian level comfort is presented by Ferreira et al. [16]. Stathopoulos [17] addressed the flow phenomena involved in the pedestrian level wind flow comfort, while Blocken et al. [18] presented a more comprehensive literature review on the broader aspects of urban flow physics and building aerodynamics.

There is a plethora of investigations in the literature on more specific cases and flow conditions of the field. Blocken and Cameliet [19] addressed the errors associated with the use of hourly sampled wind data. This is while Blocken and Cameliet [20] also presented an overview of three wind-driven rain assessment models, as well as their validations and comparisons with the theory.

Kang et al. [21] tackled the pedestrian comfort criteria dependent on the presence of nearby trees and vegetations by CFD simulations. Weerasuria et al. [22] investigated two scenarios of hot/calm and cold/windy as the setup for the optimization of the so-called lift-up design in order to maximize the wind and thermal comfort of the pedestrian level. Tsichritzis and Nokolopoulou [23] addressed the pedestrian wind comfort for the climatic case of London, targeting the optimization of building height to façade area ratio. Zhang et al. [24] presented results on the effect of different aspect ratios on the pedestrian comfort near lift-up buildings. Kang et al. [25] established a new computational fluid dynamics model for the case of trees with applications of the pedestrian level wind comfort in urban areas, and issue of multi-level wind flow characteristics in the tropical areas were addressed by Dhunny et al. [26].

In this light, the current manuscript addressed the use of a flow controlling mechanism, entitled Oblique Streamlining Membranes (OSM) implemented on the roof-top outdoor food court area of a low-rise building in the vicinity of a bulkier building, as the main wing of the whole configuration. As the problem has been tackled numerically using the RANS approach, after the introduction of the case and climatic data of the geographic point, on which the case is located, a comprehensive description of the entire CFD modelling steps and their specifications are to be followed by the results of the investigations.

\section{The case}

Nowadays it is a commonplace to establish open infrastructures and facilities, especially in multipurpose complexes, to maintain a comfortable and ingenious atmosphere. Speedy winds, however, are the most challenging issue in their design. The pressure and velocity distribution of wind flow and generated vortices should be considered in the architectural design of such facilities, otherwise, the flow disturbance and the resulted noises could be accounted as the disadvantages of those designs and reduce the attractiveness of them.

As a case study, this research has been conducted on an outdoor food court area on the roof of Trade Centre Number One's parking building, located in Shahre-Aftab International Exhibition Complex, Tehran, Iran. The aforementioned complex is located in an open area which has resulted in the high speed and frequent winds. Not only would these sorts of winds disturb the pedestrian comfort of such open infrastructures directly, but also a great deal of noise could be stemmed of this condition.

The Trade Centre Number One as shown in Figure 1, is a mall, which is under construction in the south part of Tehran, in the vicinity of Iran's deserts. Regarding Figure 2, which illustrates the 3D model of the complex, this building consists of a main cubic compartment, a three-over-ground parking building and a connecting bridge between 
those two. The main building is a five-stories, with four of them being over-ground. The height of the first three overground stories is 8 meters and the last floor, which is used for official purposes, has $5 \mathrm{~m}$ of height. On the edge of the roof are also some structures allocated to air conditioning facilities. The height of these structures is 4 meters. To sum up, the total over-ground height of the main building is 33 meters and the length and the width of this building are equally 126 meters, which are comprised from fifteen 8.4 meter modules. In the south edge of the second floor of this mall, a bridge exists, which connects the main building to the parking roof where the planned food court is going to be built. This open area is divided into two parts, east and west wing. The critical part of this open infrastructure, from an aerodynamics point of view, is the west wing of the roof, which is directly faced with the highest speed and most frequent winds.

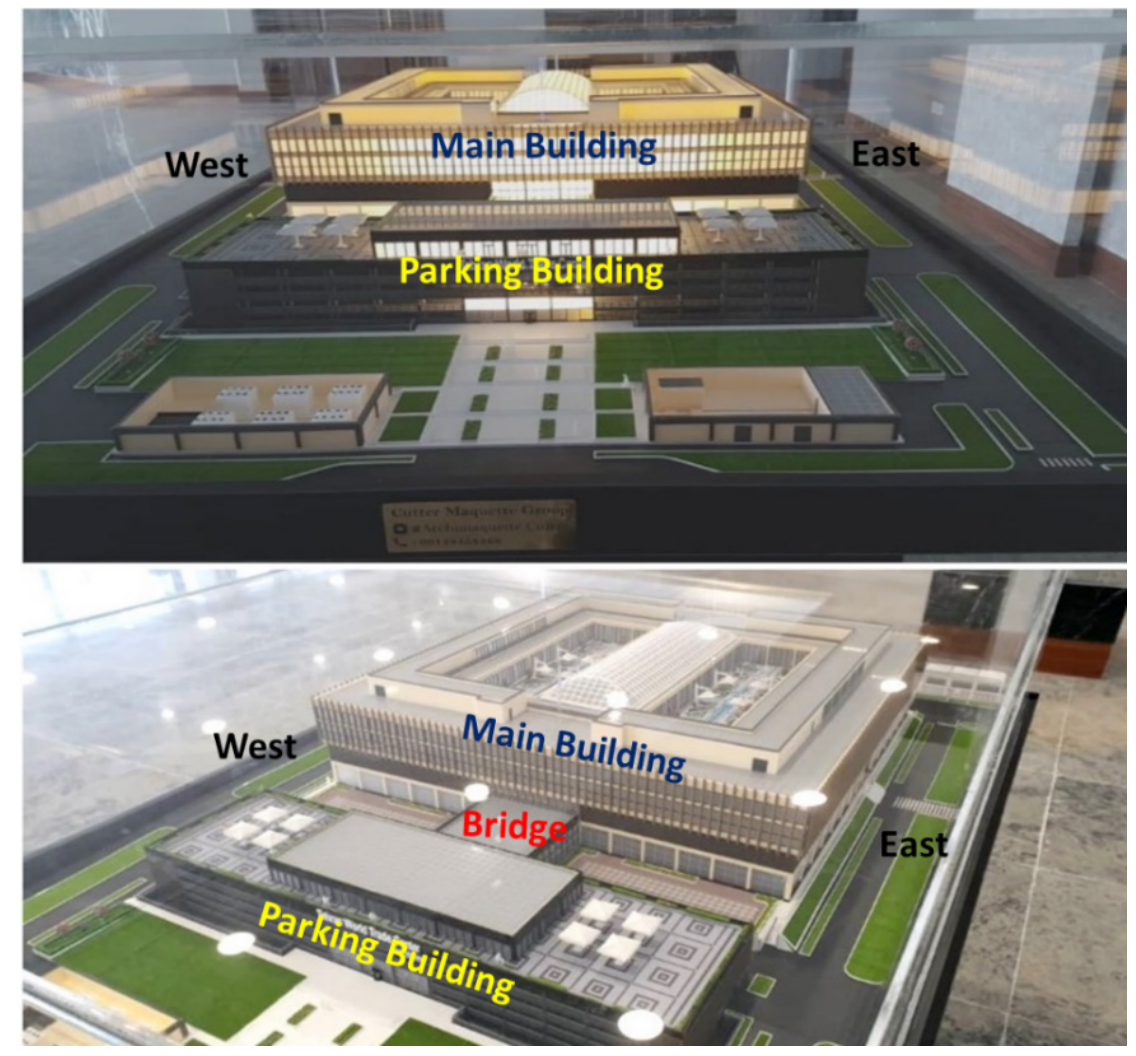

Figure 1. Scale model of the complex

The parking building, as shown in Figure 2, is a four-story building, with three of them are over the ground. Each floor has 2.6 meters of height and the roof of the building is surrounded by a $1.2 \mathrm{~m}$ parapet. In the middle of the roof, where the space is allocated to the open food court, a five-module floor with the height of $5.6 \mathrm{~m}$ exists, which is considered for indoor areas of the food court.

As depicted in Figure 3, this complex is under construction by the time of this study and it is planned to implement some obstacles to sustain a comfortable atmosphere in case of high-speed winds, namely the OSMs. This goal can be achieved by deflecting the streamlines of the wind flow or flow diffusion in the purposed area to reduce the flow speed by the local increment in the static pressure. To do so, a statistical wind study is needed. Having found the most frequent and speedy winds' velocity magnitude and direction, a 3D-CFD simulation would be conducted to find the overall flow and pressure distribution on the whole domain. Then, the modified design could be proposed based on the mentioned simulations, as they should be re-simulated by CFD calculations and iteratively corrected to reach the optimal conditions, in regard to the comfort of the pedestrian. 


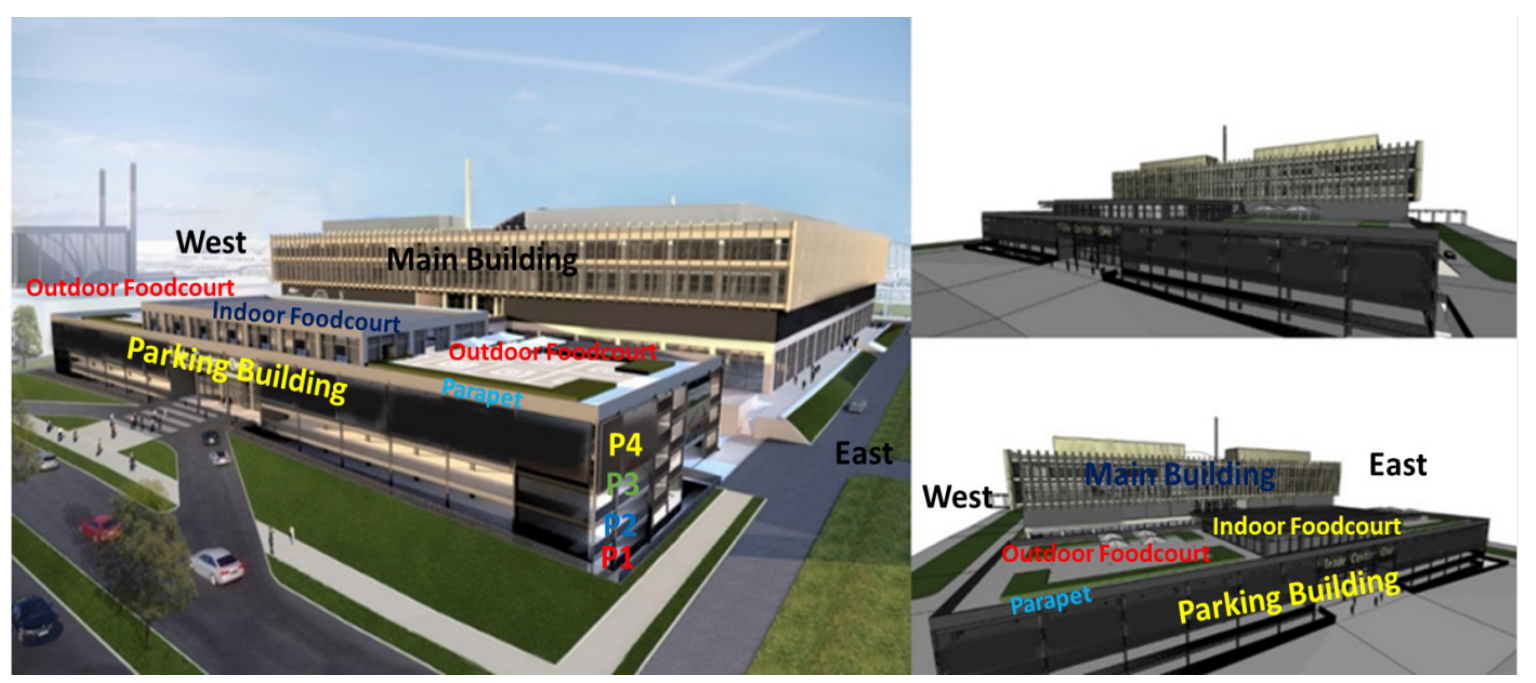

Figure 2. 3D sketches of the case

In this study, some horizontal and oblique membranes have been iteratively proposed to direct the wind flow field upward and to maintain a comfortable atmosphere in the target area. These membranes could also be used to sustain an acceptable shadow, in case of warm sunshine, especially in summer.

In the following steps of this research, the designed membrane could be motorized with some kinds of hydraulic jacks and related mechanisms to optimize the membrane installation angle, in regard to the wind direction and magnitude, and also minimize the sun radiation rate. However, under this circumstance, the power used to support such mechanism and future maintenance of it require meticulous consideration.
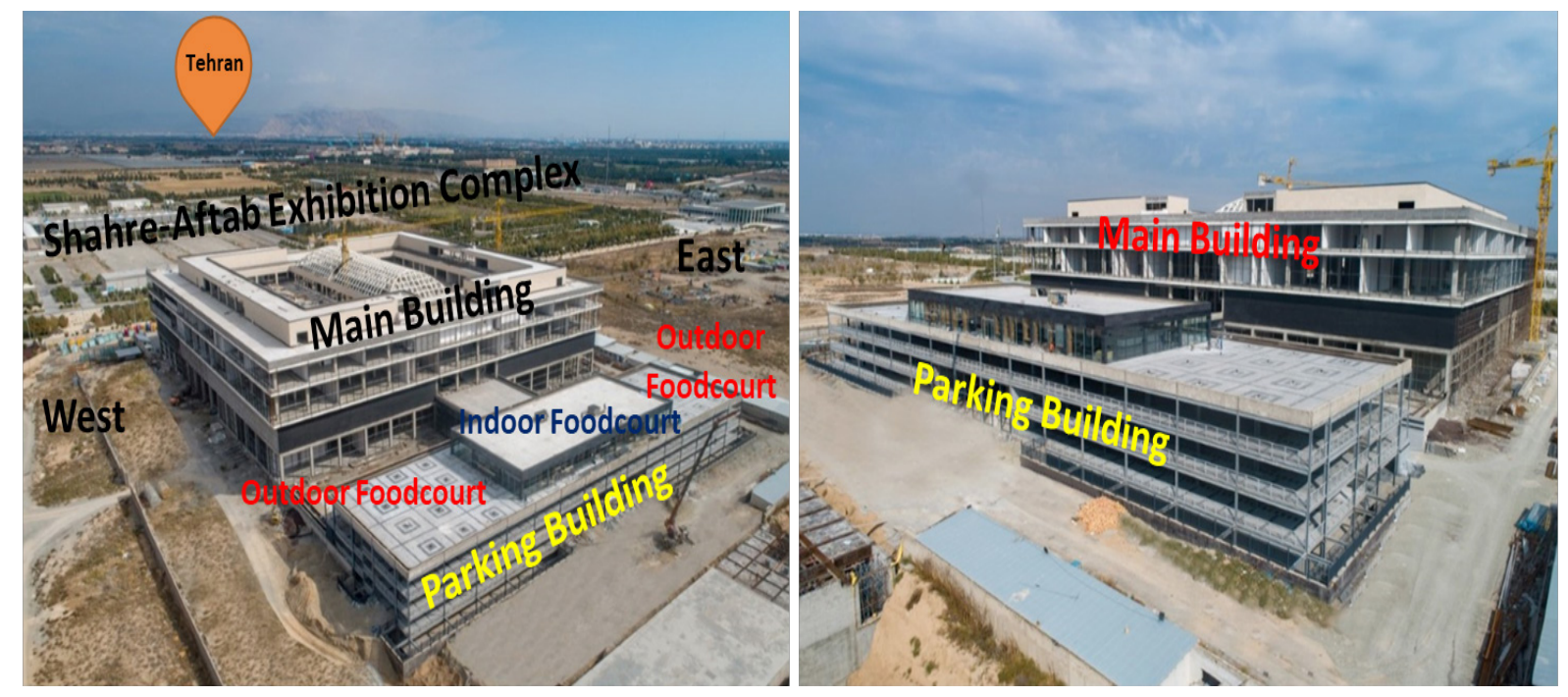

Figure 3. Actual prototype in construction phase

\section{Climatic data}

Based on the statistics published through 1991-1995 for the building site regions, the west wind is the major local wind, while the weakest winds are the ones, which breathe from the east. In addition, the velocity of the speediest winds is about $18-20 \mathrm{~m} / \mathrm{s}$. 
Besides, the east-south and north-west country winds can be mentioned as the other frequent regional winds. Wind data in Tehran stations show that the region can be divided into two, north and south parts, wind-wise. Based on research the south flows start to develop in Fashafouyeh field in the morning and dominate the whole Tehran area and in the middle of the day the whole Rey, Eslamshahr and Tehran regions are involved in south flows. As this region is located in the foothill of the Alborz mountains system, and the fact that the altitude reduces from north to south, it is usually under the influence of local winds (Figure 4).

The seasonal and local winds of this region are: Shahryar wind, which breathes from west to east in spring and its velocity is about $10-15 \mathrm{~m} / \mathrm{s}$ and it is mostly cold; and Varamin wind which breathes from east to west in summer and is known as the desert wind. Its velocity is about $5-15 \mathrm{~m} / \mathrm{s}$ and it is mostly warm.

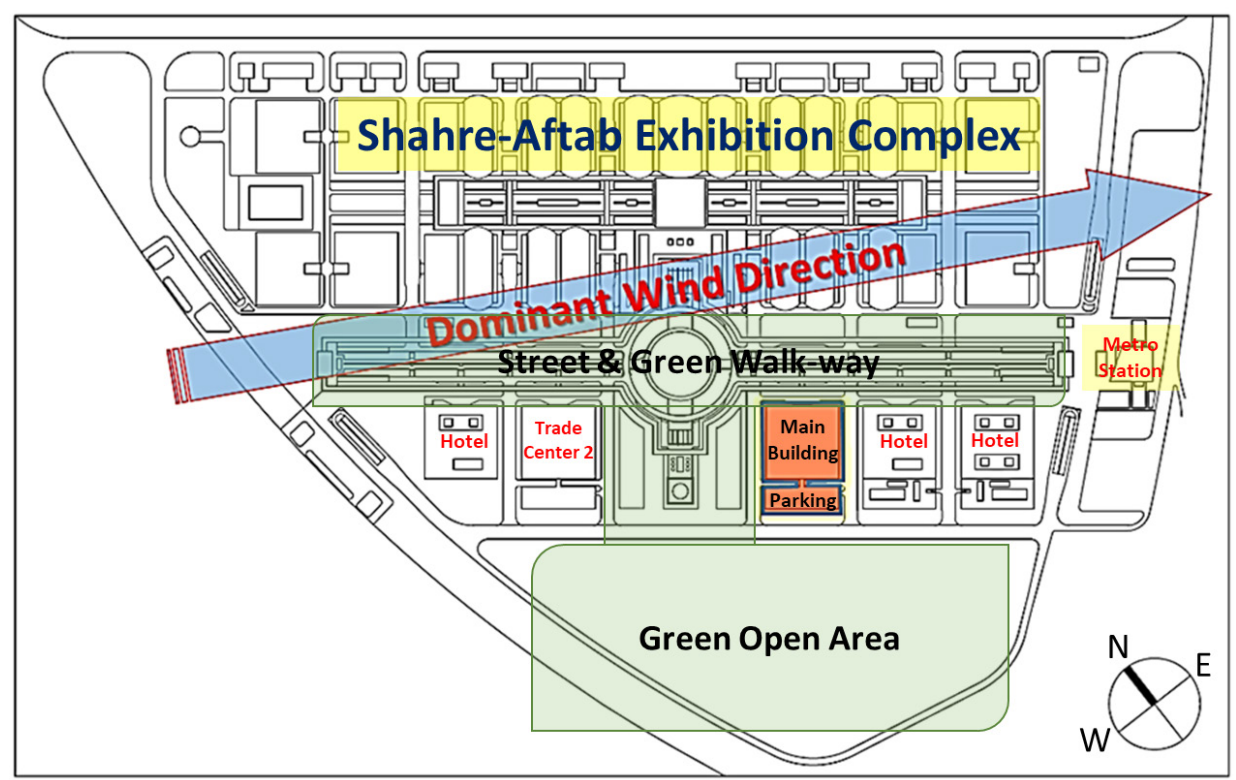

Figure 4. Dominant, local wind direction

\section{CFD modelling}

\subsection{Governing equations}

The mathematical description of the fluid flow is given by the fundamental conservation equations; namely the conservation of mass or continuity equation, the conservation of linear momentum or the fluid flow equivalent to Newton's second law of motion, and the conservation of energy or the first law of thermodynamics (Eqs. 1 to 4).

The general approach towards the solution of the conservation equations is the so-called Reynolds Average NavierStokes (RANS). The averaging process used in RANS is suitable for the flow quantities and could be applied to the entire domain.

$$
\begin{gathered}
\nabla \cdot(\rho \vec{v})=S_{m} \\
\nabla \cdot(\rho \overrightarrow{v v})=-\nabla \cdot p+(\overline{\bar{\tau}})+\rho \vec{g}+\vec{F} \\
\nabla \cdot(\vec{v}(\rho H+p))=\nabla \cdot\left(k_{e f f} \nabla T\right)+S
\end{gathered}
$$




$$
\overline{\bar{\tau}}=\mu\left[\left[\nabla \vec{v}+\nabla \vec{v}^{T}\right]-\left(\frac{2 \nabla}{3}\right) \cdot \vec{v} I\right]
$$

To model the turbulence effects in the flow field, the $\mathrm{k} \omega \mathrm{SST}$ model is chosen for the current study as common practice for the rotational flow fields of high circulation levels. In addition, the mentioned turbulence model combines the precise formulation of the $\mathrm{k} \omega$, with the simpler and less critical in convergence process of ke model. Equations 5 and 6 represent the transport equations of the $\mathrm{k} \omega$ SST model, as described in more details in the literature in Wilcox [27] and Menter [28].

$$
\begin{gathered}
\frac{\partial}{\partial t}(\rho k)+\frac{\partial}{\partial x_{i}}\left(\rho k u_{i}\right)=\frac{\partial}{\partial x_{i}}\left(\Gamma_{k} \frac{\partial k}{\partial x_{i}}\right)+\overline{G_{\omega}}-Y_{k}+S_{k} \\
\frac{\partial}{\partial t}(\rho \omega)+\frac{\partial}{\partial x_{i}}\left(\rho \omega u_{i}\right)=\frac{\partial}{\partial x_{i}}\left(\Gamma_{\omega} \frac{\partial \omega}{\partial x_{i}}\right)+\overline{G_{\omega}}-Y_{\omega}+D_{\omega}+S_{k}
\end{gathered}
$$

\subsection{Computational domain}

As mentioned in Section 2, the case entails two main building compartments with a linking bridge attaching them. In the 3D-CFD study of the case, the realistic numerical values of 126, 126 and 33 meters have been considered as length, width and height of the main building, respectively (Figure 5). Although the main flow under study surrounds the other sub-section of the building, however due to the excessive influences applied to the case by the presence of the bulky compartment, it is also considered in the computational domain of study.

The more relevant part, however, is a three-story high parking space located parallel to the previously mentioned bulky section. Both sections are connected with a walking bridge of the length $25.2 \mathrm{~m}$. The parking section is 33 meters long in the direction of the bridge main axis, and has an identical width to the main compartment, namely $126 \mathrm{~m}$. The parking section is designed to be open in all peripheral facades, with the height of $2.6 \mathrm{~m}$ in each level.

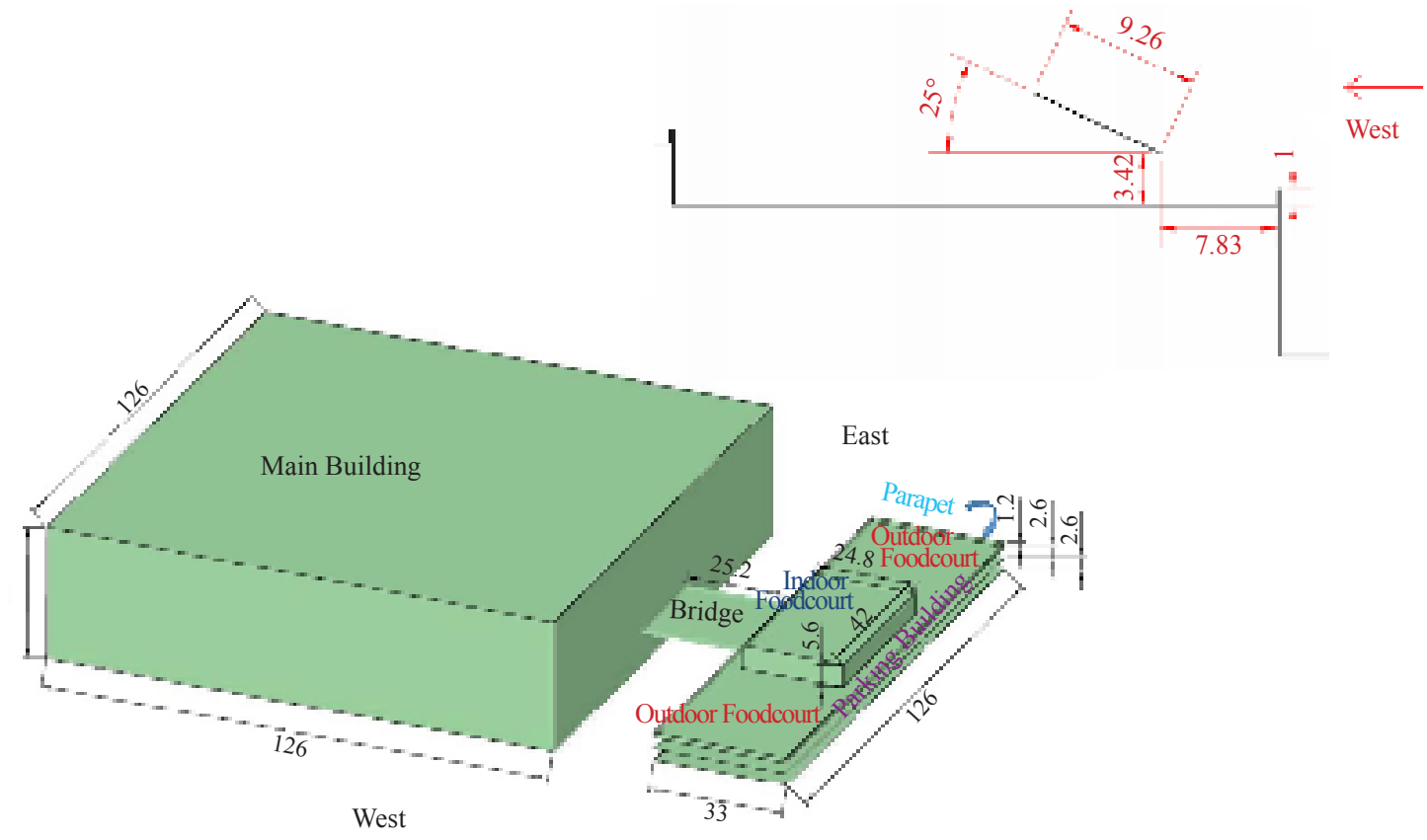

Figure 5. Geometric specifications for the 3D computational case 
On the top of the parking section, there is an open area to be used as an outdoor roof-top food court, whose flow field is the prominent subject of the current research. The indoor section of the food court is $42 \mathrm{~m}$ wide, $24.8 \mathrm{~m}$ long and $5.6 \mathrm{~m}$ high. As for safety guard, there are initially $1.2 \mathrm{~m}$ tall guards all around the roof-top, which is later subjected to optimization throughout the current study.

An oblique flow control surface has been implemented as shown in Figure 5 on the side of the roof-top adjacent to the dominant local wind flow direction, with a 25 degrees inclination angle.

\subsection{Boundary conditions}

The cubic domain of the current study, undergone by the local dominant wind direction not parallel to the main axes of the building and the computational domain, results in a geometrically difficult case for the velocity boundary conditions. To overcome that, two vertical faces of the cubic domain have been considered as the velocity inlet boundary condition, with the numerical value equal to $15 \mathrm{~m} / \mathrm{s}$, and parallel to the ground.

Consequently, the opposing two vertical sides of the domain are set to be pressure outlets with the atmospheric values. To overcome the excess volumetric flow rate due to the formation of the boundary layer on the ground, as well as to compensate the volume of the building itself, the top surface of the domain is also set to atmospheric pressure outlet.

\subsection{Numerical grid}

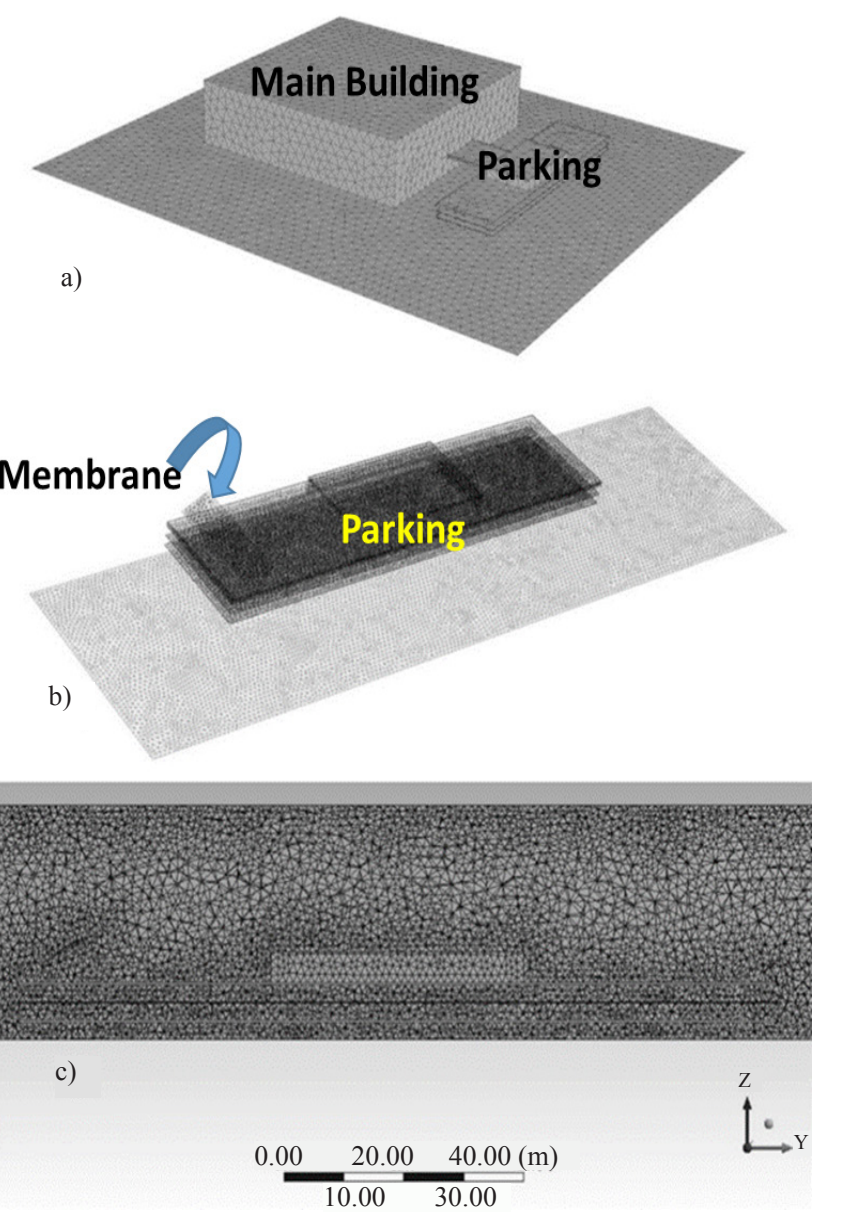

Figure 6. 3D grid; a) isometric view of the surface mesh of the base whole domain, b) the isometric view of the surface mesh of the Parking building with the deflector membrane. c) West-East section of the flow field of the Parking Building 
The numerical grid is generally comprised of tetrahedral elements growing from their primary triangular projection on the ground and building surfaces, as well as the side and top surfaces of the domain, throughout the entire volume of the domain (Figure 6). Around the main (bigger) part of the building, there are 48228 nodes and 262272 mesh elements.

The side section of the geometry understudy is floored with triangular mesh elements of 5.75 meters with the linear growth rate of 1.05 perpendicular to the surface. This results in the maximum mesh size of $11.5 \mathrm{~m}$ on the boundaries of the domain. The smaller, but more relevant, part of the building is filled with 246759 nodes and 1317432 mesh elements. It is similarly resulted from triangular mesh elements on the case surface with the growth rate of 1.2 throughout the domain volume.

\subsection{Grid independency study}

It is needed to verify the independency of the solution and the results to the set numerical grid of the flow-field domain. Doing so, the concentration of mesh on the entire domain has increased by 2.44 times excessively.

The criterion on which this issue has been studied is the velocity contour of the flow, on the target area, where the hypothetical membrane is planned to protect from direct winds. This is visually compared in Figure 7. It is plainly visible that despite infinitesimal differences between these two contours, the velocity magnitudes are generally the same with lower than $5 \%$ deviation.

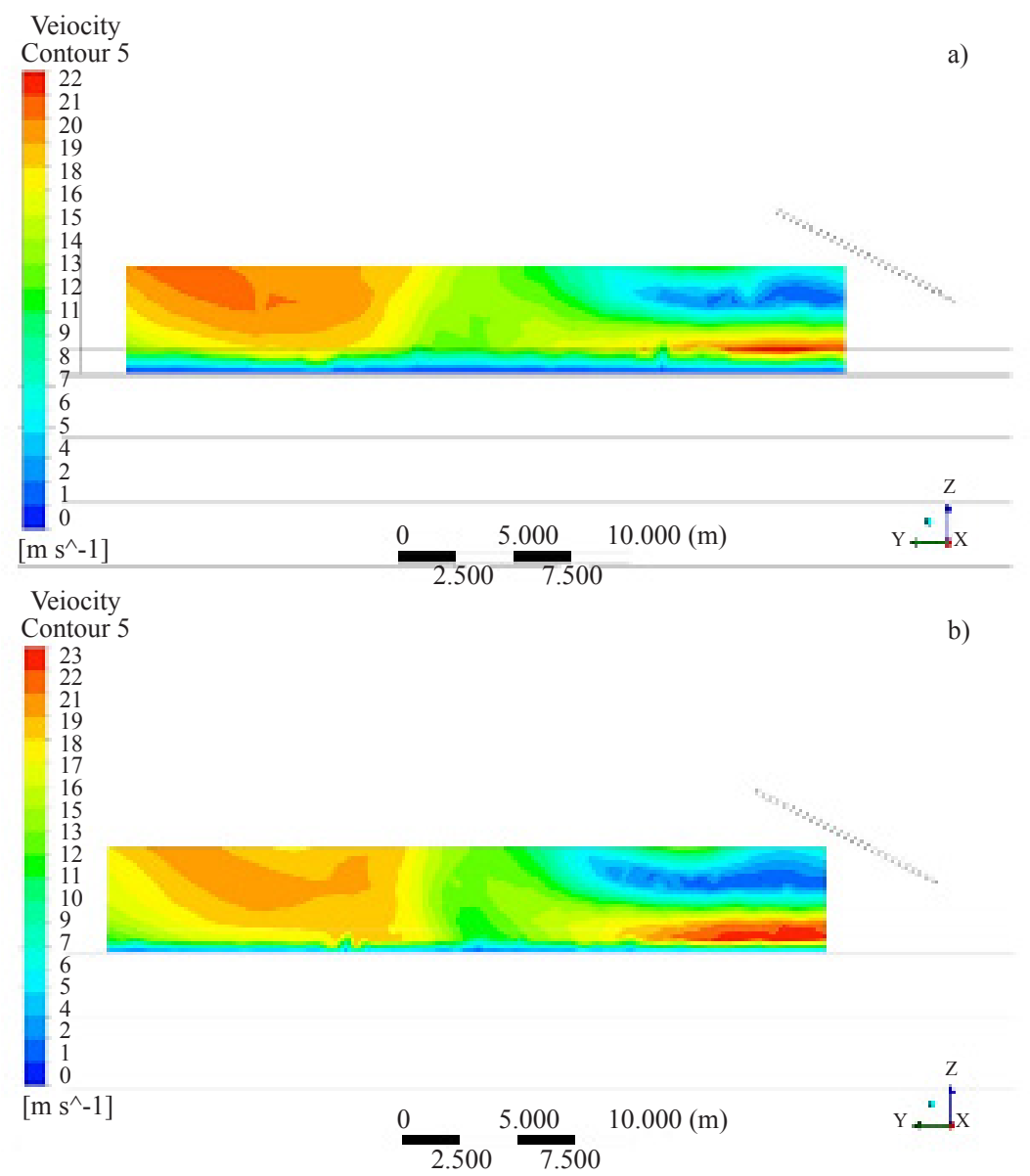

Figure 7. Velocity contours in the target area with two mesh concentrations; a) mesh concentration used in the current study, b) the finer mesh for the grid independency study purposes 


\subsection{Solver and solution methods}

The general approach to the solution of the steady RANS equations as the approximation method towards the solution of the fundamental conservative equations, is opted to be a coupling approach between the pressure and velocity. The following is a point-wise description of the solver and solution features:

- Finite Volume Method (Coupled)

- Solution Method: Pressure-Velocity Coupling

- Scheme: SIMPLE

- Gradient: Green-Gauss Node Based

- Solver Type: Pressure Based

- Time: Steady

- Velocity Formulation: Absolute

- Pressure: Second order

- Momentum: Second order-upwind

- Turbulent Kinetic Energy: First order-upwind

- Specific Dissipation Rate: First order-upwind

- Intermittency: First order-upwind

- Momentum Thickness: First order-upwind

\section{Solution method validation}

As the target building is under construction and the facade details have not been implemented yet, it is not possible to measure the real pressures and velocities on different locations to juxtapose them with the CFD results. To validate the utilized method, a number of experimental/computational similar problems are discussed in the following section.

In a survey, conducted by Gough et al. [29], a comparison between full-scale, wind-tunnel and CFD models has been made to study the influence of neighboring structures on building facade pressure distributions. In this study, a cubic shape model of a building was tested in wind-tunnel with various blowing winds direction. Simultaneously, partial and full CFD simulations were performed on this domain. Making comparison among the achieved results, the full CFD suggested pressure distribution on the surfaces, especially on wind-front ones, correspond to the full-body real pressure measurements. In the CFD study, the k $\omega$ SST turbulent model has been used similar to the present study. The SIMPLE method for coupling the pressure and velocity fields, and the second-order upwind method of discretizing the momentum equations were similar in the cited study and also presented CFD simulation.

In another study, a similar CFD wind simulation with $\mathrm{k} \omega$ SST turbulence model was performed and validated by Yuan and $\mathrm{Ng}$ [30] to investigate the influential parameters on building porosity for better urban ventilation in highdensity cities. In this research, the calculated results were compared and validated with the wind-tunnel test results published by the Architectural Institute of Japan (AIJ). The wind speed CFD simulation and wind-tunnel experimental measurements have significant correspondence.

\section{Results and discussions}

In the current case study, there is a low-rise building in the vicinity of a bulky semi-cubic building. Although the focus of this paper is on the roof area of the smaller building, however, because of the probable effects of that enormous building on the flow field of the target building, it would be fruitful to study the whole wind flow field by taking the effects of both buildings into the consideration. Regarding Figures 8 and 9, it is observable that the major wind direction, which has been applied in the numerical setup of the simulation, has 45 degrees of deviation with the building axes.

The wind flow is directed upward in the incidence with the bigger building. This condition locally increases the flow velocity on the roof of the main building, which should be taken into the consideration in the design of its outdoor elements. In the counter side of this building, the raised-velocity wind flow would result in major wakes with bulky eddies. It is important to be aware of these vortices, so that it could be helpful in the architectural design of those areas, 
both application-wise and structural-wise.

Focusing on the middle area, between these two buildings, it is clearly seen that in the current order of inlet wind velocities $(15 \mathrm{~m} / \mathrm{s})$ and direction, the main building has minor effects on the wind flow field of the parking (smaller) building. Therefore, it is worth focusing on the flow field of parking building to investigate this issue with more details.

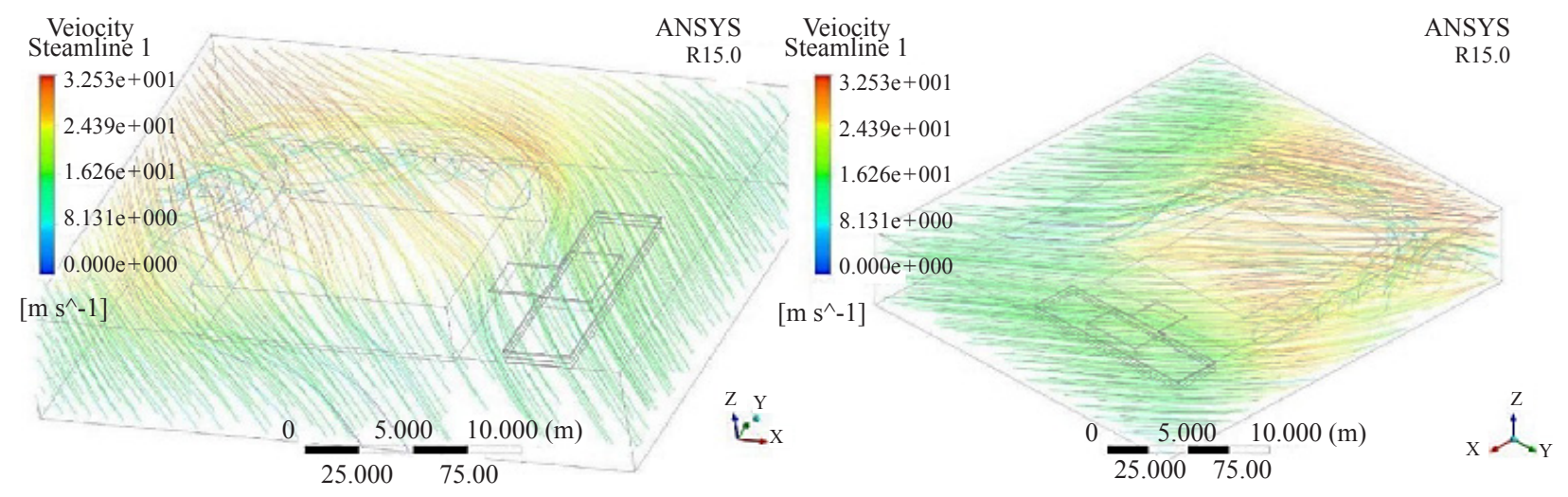

Figure 8. 3D flow field streamlines color coded based on velocity magnitude

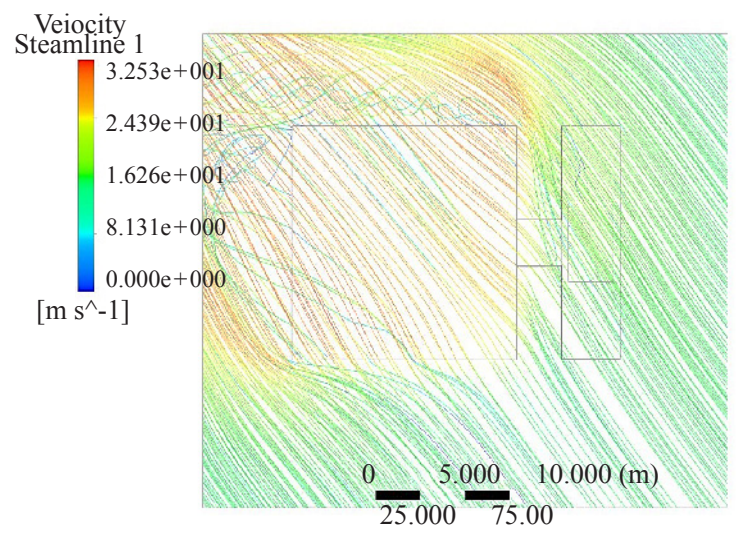

Figure 9. Flow field streamlines, color coded based on velocity magnitude-top view of the 3D domain

Figure 10 shows an eight frame north-to-south vertical velocity contour, which starts from the connective bridge. Although the velocity magnitude around the bridge is about the inlet velocity, in the left side of the contour it is shown that the velocity has increased up to $27.7 \mathrm{~m} / \mathrm{s}$. This issue will reduce the static pressure in this area.

On the west side of the building roof, the maximum velocity is about $19 \mathrm{~m} / \mathrm{s}$, which is located 4 to 5 meters away from the masonry surface of the roof, in the lower heights, however, because of the no-slip boundary condition on the roof surface, the velocity varies from its original value to a uniform, stationary condition. This would result in the pressure drop at higher levels. The front wind face of the middle roof floor decreases the wind velocity and automatically the static pressure increases, on the roof of this floor, however, the velocity increases up to $19 \mathrm{~m} / \mathrm{s}$ and as the result of that the pressure would also be dropped.

This high-speed wind imposes a wake area in the downstream of the separation point in the east side of that floor's roof parapet. Thus, in the contour side of that floor, the vertex velocity is about the original value.

In the following, the velocity reduces to the $15 \mathrm{~m} / \mathrm{s}$ and by this drop in the velocity and increment in static pressure, the wake areas are reduced.

In the south of the building, the wind speed has also increased because of the presence of the building. At this location, on the left side of the depicted contour, the velocity magnitude has increased to $17 \mathrm{~m} / \mathrm{s}$. Nevertheless, at the right side of the picture, the velocity has dropped to its origin and logically the static pressure would be recovered stream-wise. 


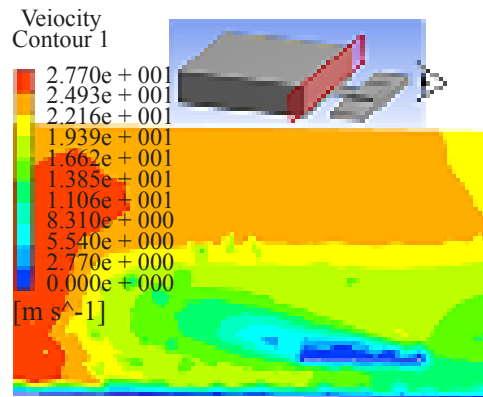

a)

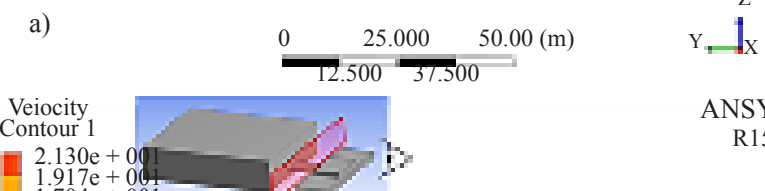

$2.130 \mathrm{e}+0$
$1.917 \mathrm{e}+$
$1.704 \mathrm{e}+001$

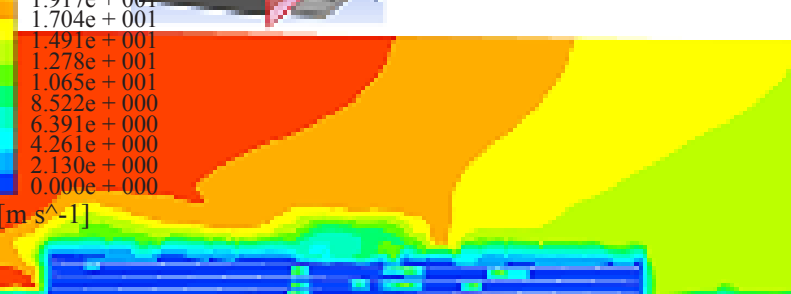

c)

Veiocity

Veiocity
Contour 1

$1.922 \mathrm{e}+00$
$1.730 \mathrm{e}+0 \mathrm{c}$

$1.730 \mathrm{e}+04$
$1.538 \mathrm{e}+001$

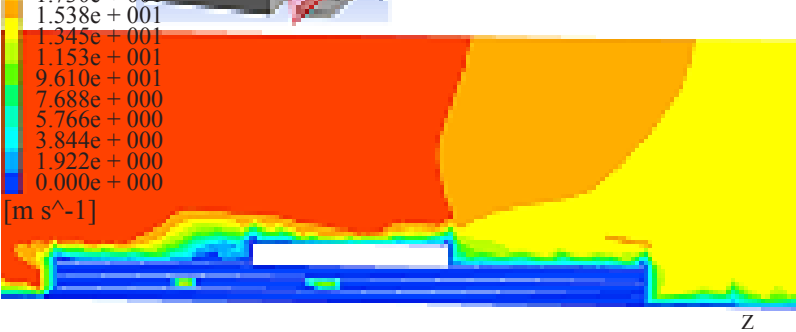

e)

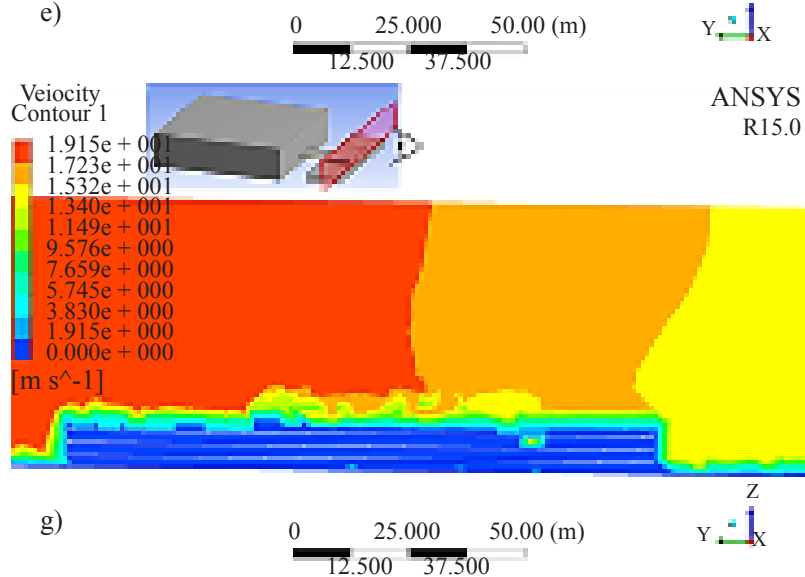

ANSYS
Veiocity
Contour 1

R15.0

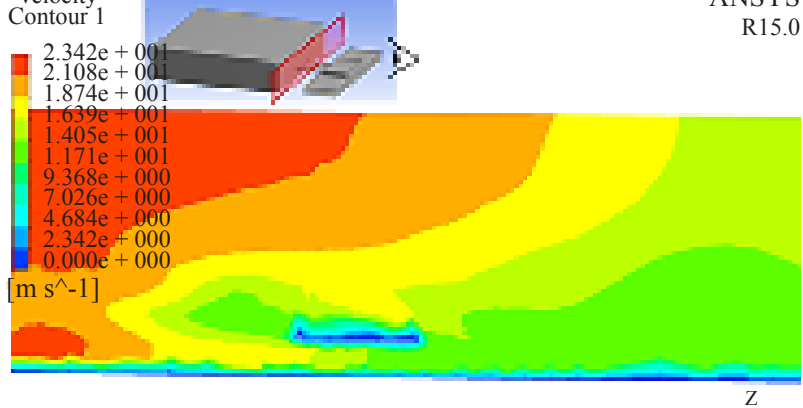

b)

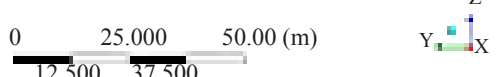

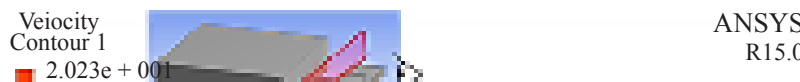

7. $2.023 \mathrm{e}+0$

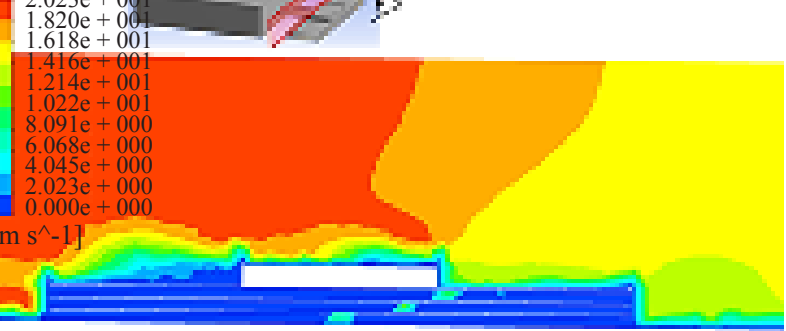

d)

$\mathrm{Y}=\stackrel{\mathrm{Z}}{\mathrm{Z}} \mathrm{X}_{\mathrm{X}}$

Veiocity
Contour 1

ANSYS

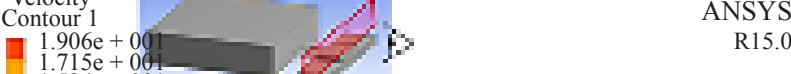

$1.715 \mathrm{e}+0 \mathrm{e}$

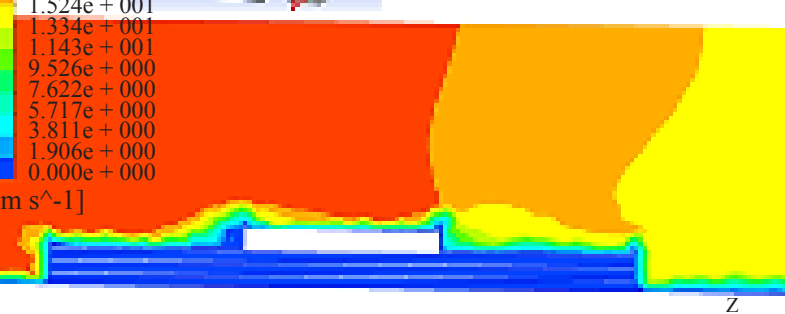

f)

$\mathrm{y}=\mathrm{k}$

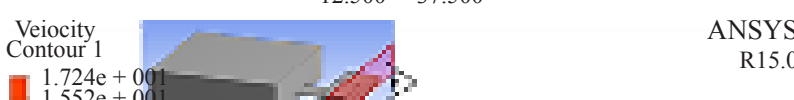

$1.724 \mathrm{e}+0$
$1.552 \mathrm{e}+0$

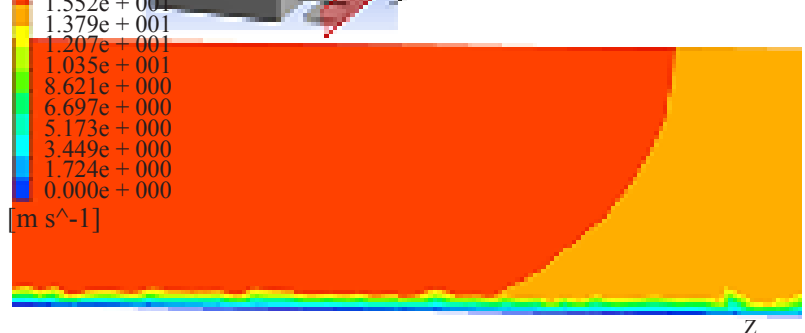

h)

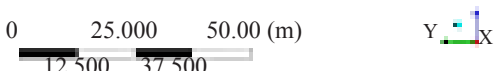

Figure 10. Velocity contour in vertical planes distributed parallel to the overall wind direction (North to South Marching)-baseline design a) on the bridge in the vicinity of the Main Building; b) in the middle of the bridge; c) on the north face of the parking building; d) $25 \%$ of parking North-South Span; e) North-South midline of the parking building; f) $75 \%$ of parking North-South Span; g) on the south face of the parking building; h) Southern open space of the parking building 

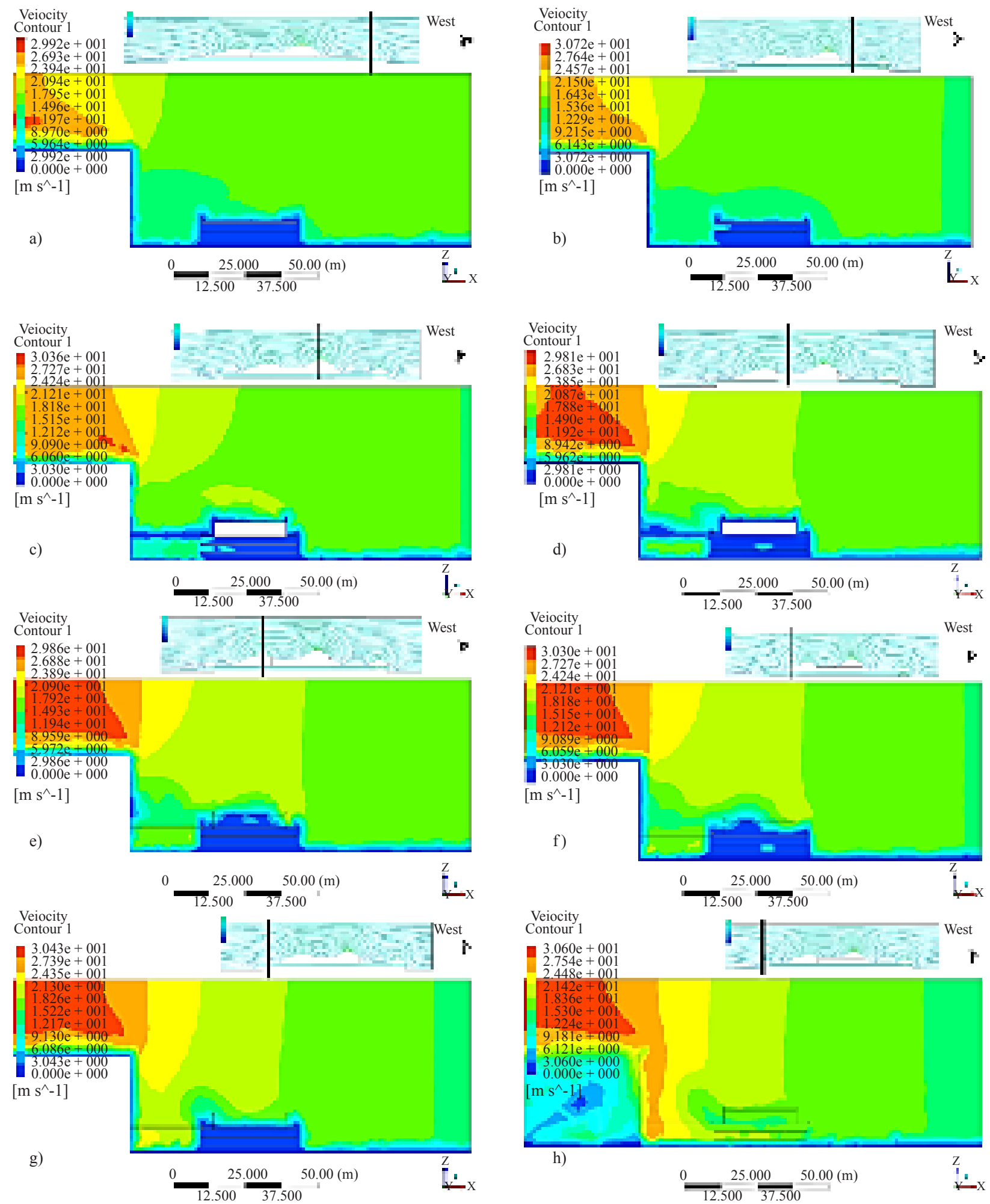

Figure 11. Velocity contour in vertical planes distributed perpendicular to the overall wind direction-baseline design,

a) on the west face of the parking building; b) in the middle of the west wing of the outdoor roof-top food-court;

c) on the west part of the indoor food-court; d) on the east part of the indoor food-court; e) on the east face of the indoor food-court; f) in the middle of the east wing of the outdoor roof-top food-court;

$\mathrm{g}$ ) on the east face of the parking building; h) in the east open area of the building 
The vertical velocity contours have been provided in Figure 11 from west to east. Perpendicular to these contours, the middle roof streamlines have also been illustrated in this figure. It is clearly seen that the closer the middle of the half floor the contour exists, the greater magnitude of velocities could be observed.

Because of the oblique flow direction, a gradient of velocity can be observed from north to south of the parking building roof. On the main roof of this building, the parapets are the main reason for this distribution. But on the wake side of that half floor, in coincidence with that oblique flow, an enormous distributed wake can be observed in the fifth and sixth sub-sections of this figure.

In the west wing of the roof (Figure 11a-b) not only has the velocity magnitudes not dwindled but also the flow has been accelerated in the region from $15 \mathrm{~m} / \mathrm{s}$ up to $18 \mathrm{~m} / \mathrm{s}$. This issue would disturb the comfort of that area, on which the open food court is planned to be established.

To address this problem, a design for a membrane has been iteratively achieved, by means of which the highvelocity flow would be directed upwards to sustain a comfortable pedestrian region there. In the rest of this study, such obstacle's geometry has been simulated and compared with these results.

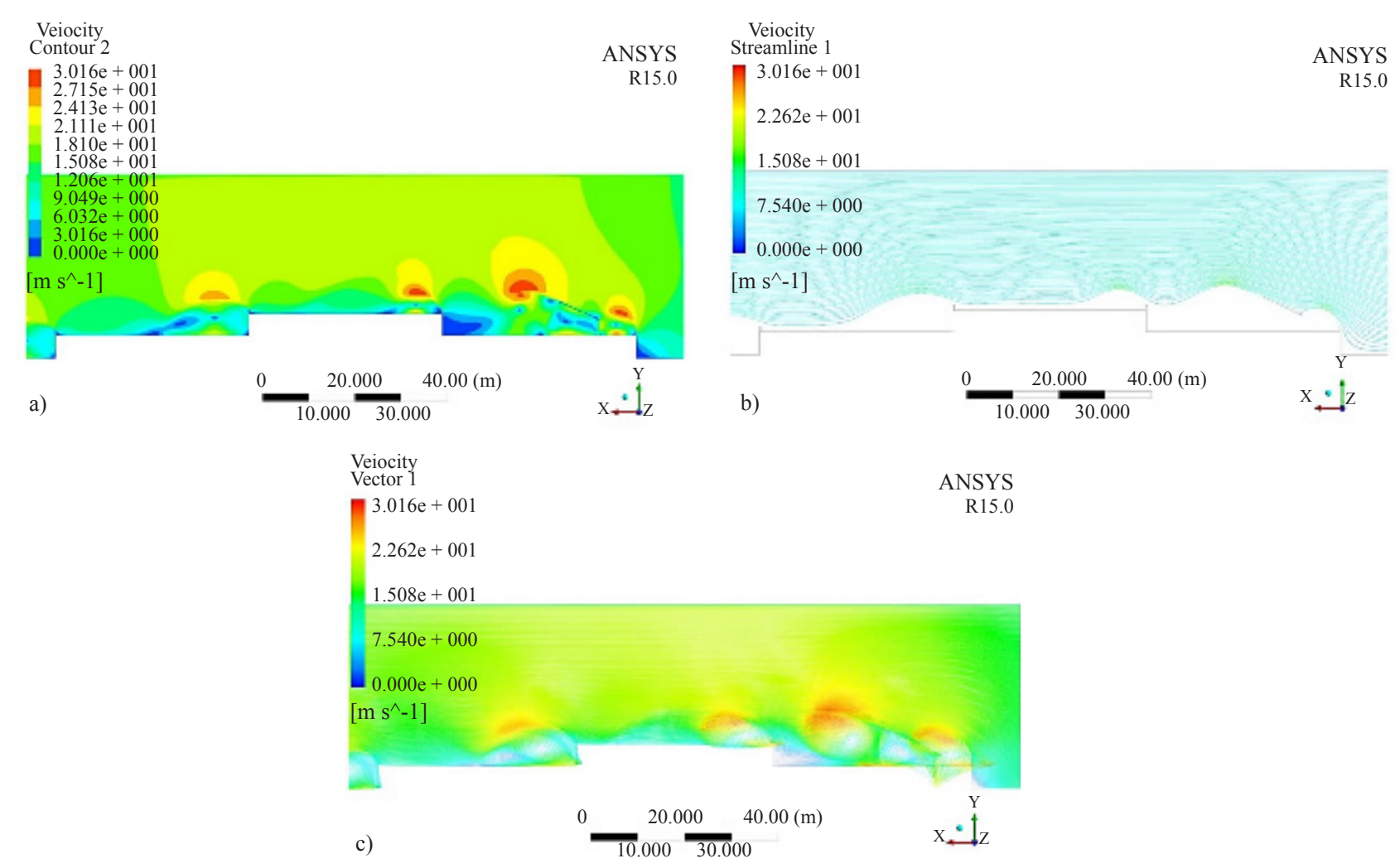

Figure 12. Flow field-OSM implemented; a) velocity contours, b) streamlines, c) velocity vectors

Regarding Figure 12, an oblique membrane has been designed for the west wing of the parking roof. The main purpose of this design is to deflect the flow streamlines to sustain a comfortable atmosphere in its downstream area. To do so, the flow should be directed upwards to be prohibited from direct confrontation with the facilities in the target area. In addition, the design should withstand the major separations to cease enormous vortices, which disturb the comfortability of the target area.

On the other hand, the main architectural factor, with which the membrane is assessed, is its vertical projected area. The lower this area is, the wider and broader the west view of the complex would be.

As shown in Figure 12, the membrane has led the inlet vectors of wind flow upward to the roof of the half-floor area in the middle of the main parking roof, where the open food court is going to be established. 
In the target domain, the velocity has decreased to about $7 \mathrm{~m} / \mathrm{s}$ from $18 \mathrm{~m} / \mathrm{s}$ in the base geometry has been simulated and reported in Figure 11. In addition to that, the reattachment of the direct wind flow field happens on the roof of the middle half-floor. Although the acceleration of the lifted flow disturbed the stability of that floor's roof pedestrian-wise, the atmospheric stability of the target area has been increased.

On the roof and the east wing of the open food court area, also, some enormous wakes can be observed, which are not under the influence of the direct flow field and secondly, they are out of the scope of this project. Nevertheless, some horizontal membranes can be predicted to withstand this issue.

Considering the streamlines, the front parapet has helped to direct the wind flow upward to the membrane leading edge and its reattachment to it. Other parapets, however, have imposed some wake flow fields on the other parts of the roof, which each one should be addressed individually. The separations these parapets imply on the flow field could have destructive effects on both masonry elements of the building. This issue should be taken into consideration in the structural design of the elements. Or they could be studied in other projects to design similar obstacles to maintain the comfortability of the other parts of the roof (Figure 13).

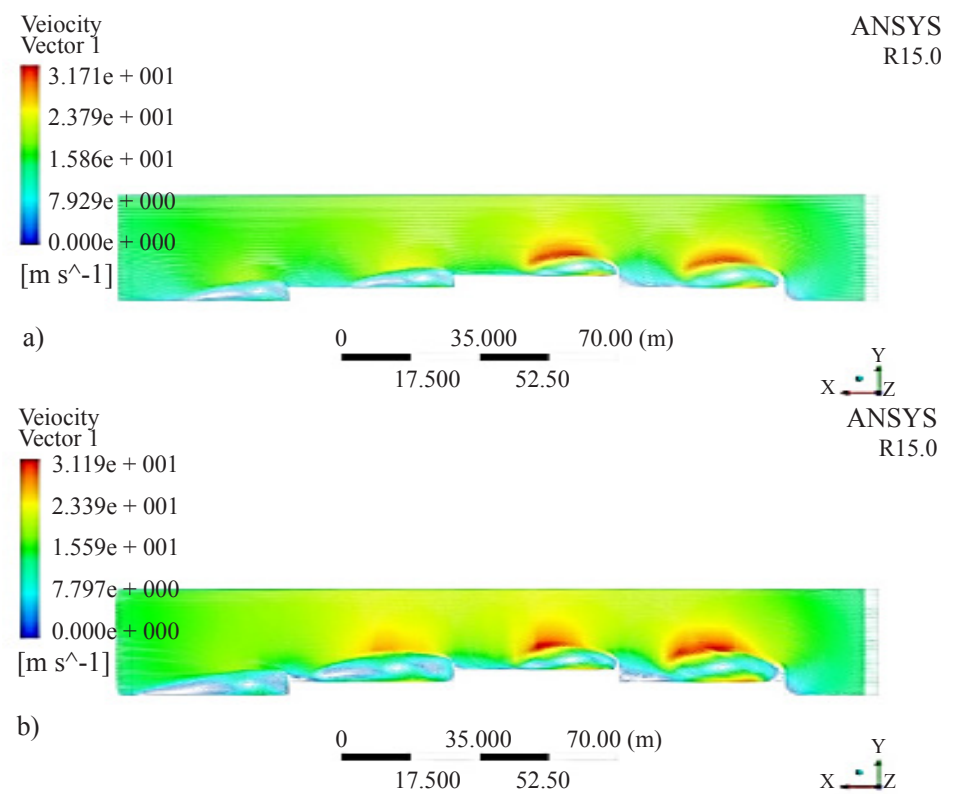

Figure 13. Safety edge effect-a) $2 \mathrm{~m}$, b) $3 \mathrm{~m}$

In summary, it is worth going through a stepwise structure of the current work once more, from the problem definition up to the point of flow field phenomenological and final evaluations, at this stage. The following pointwise list addresses the major milestones of the current flow field investigation targeting proof of concept level assessment for the suggested flow controlling mechanism, namely OSM:

- Given the demanded roof-top outdoor food court from the architectural sector of the design, the aerodynamics problem emerged in response to the pedestrian comfort criteria of the urban planning and physics disciplines.

- Considering the interconnected and nonlinear induction of flow phenomena between the part of the building designed for the mentioned food court, and the neighboring ones, the geometry for 3D-CFD investigations was chosen to include all major bodies in the site of the building, comprehensively.

- Having such a full-scale geometry with a considerable domain of interrogation stretched in all directions to capture flow phenomena propagated from the downstream of the field, an extreme number of computational mesh elements were to be implemented around the body and over the ground level in the entire domain.

- As a novelty of geometric consideration of the case, several layers of secondary flow phenomena such as those formed within the levels of the parking, or the ones resulted by the existence of the connecting bridge are noteworthy.

- Opting a high demand turbulence model for a geometry of roughly $150 \mathrm{~m}$ long, has caused enormous values of 
Reynolds number in the hundreds of millions, resulting in challenging convergence of the numerical investigations.

- The implementation of OSM with strong circulations induced to the local flow field in its near vicinity has then led to maintaining the fluctuations in the flow in a tolerable range for the residents of the roof-top area, as discussed in details in the current sections of the manuscript.

The velocity magnitudes of the base geometry model and the model with the presence of the OSM have been juxtaposed in Table 1. The mentioned parameters have been reported for different heights from the roof-top and various distances from the leading edge of the membrane. It is also calculated from the results of the velocity field, that the average velocity magnitude in the height of 1.5 and 2 meters is $10.3 \mathrm{~m} / \mathrm{s}$ for the base geometry, while the corresponding value for the OSM implemented model is $7.1 \mathrm{~m} / \mathrm{s}$.

Table 1. Numerical value comparisons of the baseline design (BL), and the OSM implemented case (OSM)

\begin{tabular}{|c|c|c|c|c|c|c|c|c|c|c|c|c|c|c|c|c|c|c|c|c|}
\hline \multirow{2}{*}{$\begin{array}{l}\mathrm{D}[\mathrm{m}] \\
\mathrm{H}[\mathrm{m}]\end{array}$} & \multicolumn{2}{|c|}{3} & \multicolumn{2}{|c|}{6} & \multicolumn{2}{|c|}{9} & \multicolumn{2}{|c|}{12} & \multicolumn{2}{|c|}{15} & \multicolumn{2}{|c|}{18} & \multicolumn{2}{|c|}{21} & \multicolumn{2}{|c|}{24} & \multicolumn{2}{|c|}{27} & \multicolumn{2}{|c|}{30} \\
\hline & OSM & BL & OSM & BL & OSM & BL & OSM & BL & OSM & BL & OSM & BL & OSM & BL & OSM & BL & OSM & BL & OSM & BL \\
\hline 0.5 & 13 & 4 & 18 & 4 & 16 & 4 & 4 & 4 & 7 & 4 & 10 & 4 & 4 & 4 & 4 & 4 & 2 & 4 & 2 & 4 \\
\hline 1.0 & 10 & 4 & 17 & 4 & 15 & 4 & 5 & 6 & 8 & 6 & 15 & 6 & 7 & 6 & 6 & 6 & 4 & 6 & 3 & 6 \\
\hline 1.5 & 5 & 19 & 13 & 10 & 6 & 10 & 6 & 10 & 9 & 10 & 15 & 10 & 7 & 10 & 5 & 10 & 3 & 9 & 3 & 6 \\
\hline 2.0 & 5 & 12 & 10 & 12 & 6 & 12 & 8 & 12 & 9 & 12 & 14 & 12 & 7 & 12 & 5 & 12 & 3 & 9 & 3 & 6 \\
\hline 2.5 & 4 & 14 & 6 & 13 & 6 & 13 & 10 & 13 & 10 & 13 & 13 & 13 & 7 & 13 & 5 & 13 & 3 & 9 & 3 & 6 \\
\hline 3.0 & 6 & 15 & 6 & 14 & 7 & 14 & 15 & 14 & 13 & 14 & 13 & 14 & 7 & 14 & 5 & 14 & 4 & 10 & 3 & 6 \\
\hline
\end{tabular}

\section{Conclusion}

In this project, an Oblique Streamlining Membrane (OSM) has been iteratively designed on an outdoor roof-top food court to sustain the pedestrian comfort in that area, as a case study. To do so, a statistical wind study was conducted to determine the direction and velocity magnitude of the major local wind. Then, a 3D-CFD steady RANS simulation was performed on the whole domain to recognize the flow field patterns and probable effects of the main building on the parking area flow field. Having found out the partial independency of these two buildings' wind flow field, a series of primary ideas have been simulated and tested on the purposed area to alleviate the direct wind effects on their pedestrian comfortability. The final concept suggested, which is the most applicable one, has been addressed in detail within the current manuscript.

As discussed under the climatic conditions, the major wind in the region is the West-to-East one and its most frequent maximum velocity magnitude is about $14-15 \mathrm{~m} / \mathrm{s}$. The direction of this wind has generally 45 degrees of deviation with the building axes. These magnitude and direction were set as the inlet boundary conditions of the simulations.

Initially, the open area on the roof has been simulated without any obstacle. It was found that the wind flow accelerates on that region up to $19 \mathrm{~m} / \mathrm{s}$, which would be considerably destructive for the comfort of the residents of the planned food court. In addition, there are some wake areas and flow separation points, which could impose negative effects on the ideal calm atmosphere of a food court.

An oblique streamlining membrane has, then, been proposed to be installed on the left wing of the roof to maintain the stability of the purposed area, in cases of speedy wind gusts. This element directs the wind upward and reattaches it to the surface on the roof of the half floor, located in the middle of the roof-top. This issue imposes a calm atmosphere in the west wing of the roof, where the food court is planned to be positioned. The velocity magnitude has then been reduced to lower than $7 \mathrm{~m} / \mathrm{s}$, which its corresponding vortices could also be vanquished by furniture installation.

To wrap up, using masonry elements besides considering their interaction with wind flows can be fruitful to provide acceptable stability in the pedestrian domain. To do this, the velocity magnitudes, flow separation and flow reattachment to the surfaces should be taken into the meticulous consideration.

Considering the current scope of the project, a rather comprehensive portion of the future extension of the research 
could cover measurement results after finalization of the construction of the building. Validation of the 3D-CFD results with the actual measurements on site would lead to fine modification of the flow controlling mechanism suggested and proven conceptually within the current manuscript.

Furthermore, expanding the concept of Oblique Streamlining Membranes (OSMs) by implementing it on other typical urban landmarks could also be of great interest, since such cases often suffer from weak airflow in their surrounding for having sharp edges and non-streamlined geometries. Another step towards modification and expansion of the presented concept of OSMs would be controllable OSMs, responding to upcoming wind configurations of a certain range in direction and magnitude, and changing their orientation, length or such trivial mechanisms. This would lead to a more optimal operation of the OSMs for all wind conditions.

It is worth mentioning that, a functional perspective in urban physics problems is always in compensation with the aesthetic and artistic aspects of the urban and architecture concerns. Although, this could be counted as a limitation to the mechanical mechanisms for purely fluid dynamics driven or energy consumption minimization targets, however, a hand in hand iterative design process would make it possible to reach to a design that able to concerns of both mentioned disciplines.

\section{Acknowledgements}

The authors would like to thank the authorities of the Cashalot construction and investment company and the GMP Architecture Inc. for outsourcing the aerodynamics investigation of the flow field streamlining of the case in question to our research team.

\section{References}

[1] Castro IP, Robins AG. Flow around a surface-mounted cube in uniform and turbulent streams. Journal of Flluid Mechanics. 1977; 79: 307.

[2] Cermak JE. Applications of fluid mechanics to wind engineering-A freeman scholar lecture. Journal of Fluids Engineering. 1975; 97(1): 9-38.

[3] Irwin PA. Bluff body aerodynamics in wind engineering. Journal of Wind Engineering \& Industrial Aerodynamics. 2008; 96(6-7): 701-712.

[4] Richards PJ, Hoxey RP, Short LJ. Wind pressures on a $6 \mathrm{~m}$ cube. Journal of Wind Engineering \& Industrial Aerodynamics. 2001; 89: 1553-1564.

[5] Richards PJ, Hoxey RP. Wind loads on the roof of a $6 \mathrm{~m}$ cube. Journal of Wind Engineering \& Industrial Aerodynamics. 2008; 96: 984-993.

[6] Mirsadeghi M, Costola D, Blocken B, Hensen JLM. Review of external convective heat transfer coefficient models in building energy simulation programs: implementation and uncertainty. Applied Thermal Engineering. 2013; 56: 134-151.

[7] Defraeye T, Blocken B, Carmeliet J. Convective heat transfer coefficients for exterior building surfaces: Existing correlations and CFD modelling. Energy Conversion and Management. 2011; 52: 512-522.

[8] Van HT, Blocken B. Coupled urban wind flow and indoor natural ventilation modelling on a high-resolution grid: A case study for the Amsterdam Arena stadium. Environmental Modelling \& Software. 2010; 25: 51-65.

[9] Shi X, Zhu Y, Duan J, Shao R, Wang J. Assessment of pedestrian wind environment in urban planning design. Landscape and Urban Planning. 2015; 140: 17-28.

[10] Aregger H, Glaus O. Highrise Building and Urban Design. FA Praeger. 1967.

[11] Blocken B. Computational fluid dynamics for urban physics: Importance, scales, possibilities, limitations and ten tips and tricks towards accurate and reliable simulations. Building and Environment. 2015; 91: 219-245.

[12] Kasra A, Seyed MM, Elnaz R, Amir FN. Numerical investigation on the convection heat transfer and drag reduction by utilizing the designed flow controlling blades on a smart sustainable house. Energy Efficiency. 2019; 12(3): 757776.

[13] Kasra A, Alireza M. 2D-CFD analyses of flow controlling plates on gable roof geometry cross-sections for light air to strong breeze wind speed classifications-an unsteady RANS approach. Green Building and Construction Economics. 2020; 1(1): 1-20. 
[14] Tominaga Y, Mochida A, Yoshie R, Kataoka H, Nozu T, Yoshikawa M, et al. AIJ guidelines for practical applications of CFD to pedestrian wind environment around buildings. Journal of Wind Engineering \& Industrial Aerodynamics. 2008; 96(10-11): 1749-1761.

[15] Blocken B, Carmeliet J, Stathopoulos T. CFD evaluation of wind speed conditions in passages between parallel buildings-effect of wall-function roughness modifications for the atmospheric boundary layer flow. Journal of Wind Engineering \& Industrial Aerodynamics. 2007; 95(9-11): 941-962.

[16] Ferreira AD, Sousa ACM, Viegas DX. Prediction of building interference effects on pedestrian level comfort. Journal of Wind Engineering \& Industrial Aerodynamics. 2002; 90(4-5): 305-319.

[17] Stathopoulos T. Pedestrian level winds and outdoor human comfort. Journal of Wind Engineering and Industrial Aerodynamics. 2006; 94(11): 769-780.

[18] Blocken B, Stathopoulos T, Beeckd van JPAJ. Pedestrian-level wind conditions around buildings: Review of windtunnel and CFD techniques and their accuracy for wind comfort assessment. Building and Environment. 2016; 100: $50-81$.

[19] Blocken B, Carmeliet J. On the errors associated with the use of hourly data in wind-driven rain calculations on building facades. Atmospheric Environment. 2007; 41(11): 2335-2343.

[20] Blocken B, Carmeliet J. Overview of three state-of-the-art wind-driven rain assessment models and comparison based on model theory. Building and Environment. 2010; 45(3): 691-703.

[21] Kang G, Kim JJ, Choi W. Computational fluid dynamics simulation of tree effects on pedestrian wind comfort in an urban area. Sustainable Cities and Society. 2020; 56: 102086. Available from: https://doi.org/10.1016/ j.scs.2020.102086.

[22] Weerasuriya AU, Zhang XL, Lu B, Tse KT, Liu CH. Optimizing lift-up design to maximize pedestrian wind and thermal comfort in 'hot-calm' and 'cold-windy' climates. Sustainable Cities and Society. 2020; 58: 102146. Available from: https://doi.org/10.1016/j.scs.2020.102146.

[23] Leonidas T, Marialena N. The effect of building height and facade area ratio on pedestrian wind comfort of London. Journal of Wind Engineering and Industrial Aerodynamics. 2019; 191: 63-75.

[24] Zhang XL, Tse KT, Weerasuriya AU, Li SW, Zhang L, Kwok KCS, Cheuk MM, Niu JL. Evaluation of pedestrian wind comfort near 'lift-up' buildings with different aspect ratios and central core modifications. Building and Environment. 2017; 124(1): 245-257.

[25] Kang G, Kim JJ, Kim DJ, Choi W, Park SJ. Development of a computational fluid dynamics model with tree drag parameterizations: Application to pedestrian wind comfort in an urban area. Building and Environment. 2017; 124(1): 209-218.

[26] Dhunny AZ, Samkhaniani N, Lollchund MR, Rughooputh SDDV. Investigation of multi-level wind flow characteristics and pedestrian comfort in a tropical city. Urban Climate. 2018; 24: 185-204.

[27] Wilcox D. Turbulence modeling for CFD. La Canada, CA: DCW Industries; 2006.

[28] Menter F. Two-equation eddy-viscosity turbulence models for engineering applications. AIAA J. 1994; 32(8): 1598-1605.

[29] Gough H, King MF. Influence of neighboring structures on building façade pressures: Comparison between fullscale, wind-tunnel, CFD and practitioner guidelines. Journal of Wind Engineering \& Industrial Aerodynamics. 2019; 189: 22-33.

[30] Yuan C, Ng E. Building porosity for better urban ventilation in high-density cities-A computational parametric study. Journal of Building and Environment. 2012; 50: 176-189. 